\title{
Finger clubbing and aspartylglucosamine excretion in a laxative-abusing patient
}

\author{
J. MALMQuist* \\ M.D. \\ B. ERICSSON† \\ M.D. \\ M.-B. HultÉn-NossLinł \\ J.-O. JEPPSSON $\S$ \\ M.D. \\ M.D. \\ O. LJUNGBERG \\ M.D. \\ Departments of *Medicine, $\uparrow$ Surgery, $\ddagger$ Psychiatry, §Clinical Chemistry, and $\uparrow$ Pathology, \\ University of Lund, Malmö General Hospital, Malmö, Sweden
}

\begin{abstract}
Summary
A young woman with a previous history of anorexia nervosa presented with severe finger clubbing. Urine samples intermittently contained significant amounts of aspartylglucosamine. Liver biopsy showed abnormal cytoplasmic inclusions in phagocytic cells. The patient was found to be abusing senna laxative.

\section{Introduction}

Among disturbances caused by excessive use of laxatives, reversible finger clubbing has been reported (Silk, Gibson and Murray, 1975; Prior and White, 1978).

Abnormalities of bone, connective tissue, and skin are part of the clinical syndrome in the hereditary biochemical disturbance aspartylglucosaminuria (Jenner and Pollitt, 1967), although finger clubbing has not been noted in detailed clinical studies (Autio, 1972).

This report concerns a patient who presented with an association of the above conditions.

\section{Case report}

The female patient was born in 1945 and brought up by her mother only, having no contact with her father. No information indicates consanguinity. The mother's age at the patient's birth was 39 years. There were no siblings. She had permanent amenorrhoea since 1966, starting after cessation of contraceptive steroids. From 1967, severe neuroticdepressive problems culminated in anorexia nervosa with marked emaciation (body weight minimum $26 \mathrm{~kg}$, height $1.56 \mathrm{~m}$ ) during the period 1969-1974. From 1972 there was considerable abuse of alcohol and sedatives but later, improvement and stabil-
\end{abstract}

ization occurred on a controlled regimen of $\rightarrow$ tranquillizers and hypnotics. She was regularly seen by a psychiatrist, her main complaints being $\overparen{\Phi}$ restlessness, tension, insomnia, low self-esteem, 3 and contact problems. Her intelligence was assessed 믐 as average. She was employed as an office clerfo working with computer tape punching.

In 1973, she was admitted to a surgical departmer with abdominal pain but laparotomy disclosed no acute abdominal disease. The colon was seen to be generally dilated, and the liver was unusually small and dark-coloured.

Later in 1973 she was re-admitted because of leg $\stackrel{\mathbb{Q}}{\varrho}$ oedema and ascites. The fluid retention abated $\overrightarrow{\overrightarrow{0}}$ during a period of frusemide and spironolactone. 3 Percutaneous liver biopsy showed normal tissue $\vec{P}$ architecture. The only abnormal histological finding was the presence of rather large, polyhedric cells $\overline{0}$ occurring singly or in groups of a few cells within 3 . the portal connective tissue and the liver tissue (Fig. 1). These cells, which were interpreted as $\frac{3}{3}$. macrophages, were filled with a particulate material $\delta$ which contained occasional large vacuoles. These cytoplasmic inclusions showed a positive PAS 옹 reaction which remained positive after the applic- $\rightarrow$ ation of diastase. They also stained positively with a method for the demonstration of acid phosphatase $N$ on frozen sections (Barka and Anderson, 1962), suggesting that the material was lysosomal in nature. 0

In 1975 the patient was referred because of $\underset{\omega}{N}$ finger clubbing, ankle oedema, and some facial $\bar{Z}$ puffiness. The fluid retention disappeared without 0 treatment but finger clubbing remained (Fig. 2). No other physical or cardiopulmonary abnormalities $\stackrel{\mathcal{C}}{?}$ were found. Body weight was $48 \mathrm{~kg}$; X-ray showed 


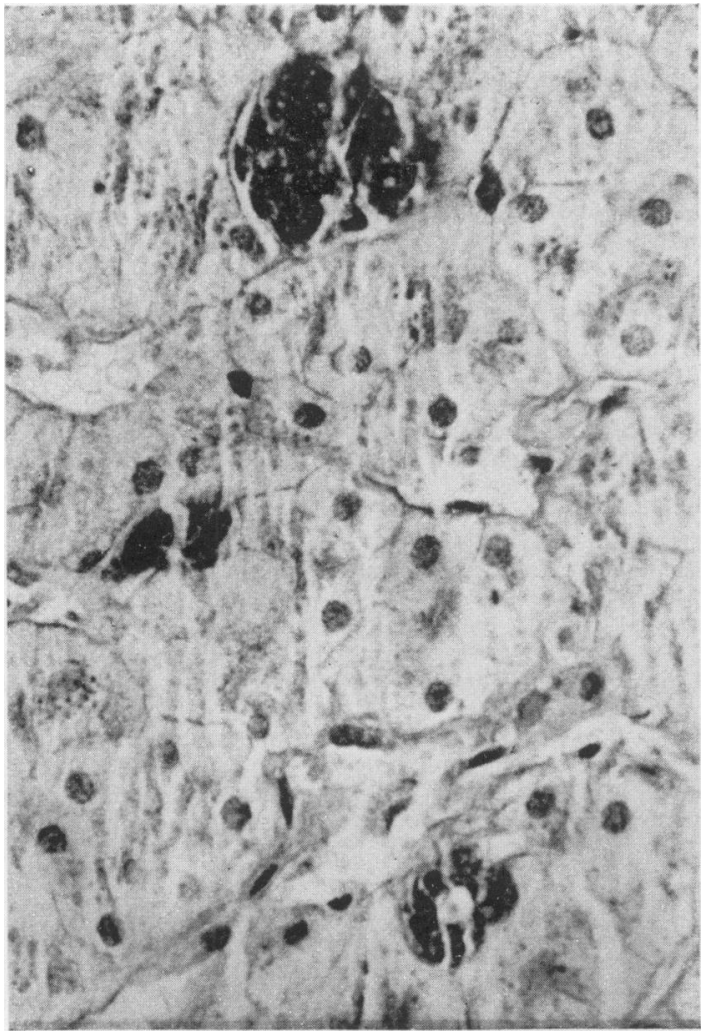

FIG. 1. Liver specimen with groups of macrophages filled with particulate PAS positive material which contains clear vacuoles (Frozen section, PAS stain, $\times 860)$.

the finger clubbing to be due solely to soft tissue thickening, with no skeletal or periosteal abnormality in the fingers but the radius bones were abnormally curved.

Since a metabolic disturbance was suspected, urinary metabolites were studied with high-voltage electrophoresis. A pathological fraction was seen close to the location of ampicillin. Ion exchange chromatography after acid hydrolysis showed an increase in aspartic acid and the appearance of glucosamine, compared to chromatography before hydrolysis. This indicated the abnormal component to be aspartylglucosamine, and was found in 2 urine samples, the amount excreted being about $400 \mu \mathrm{mol} / 24 \mathrm{hr}$. In a later sample, however, the abnormality was not seen. Except for a very minor proteinuria and slightly subnormal plasma immunoglobulins, no other pathological laboratory findings were made. There were no vacuoles in blood lymphocytes.

The enzyme deficient in aspartylglucosaminuria

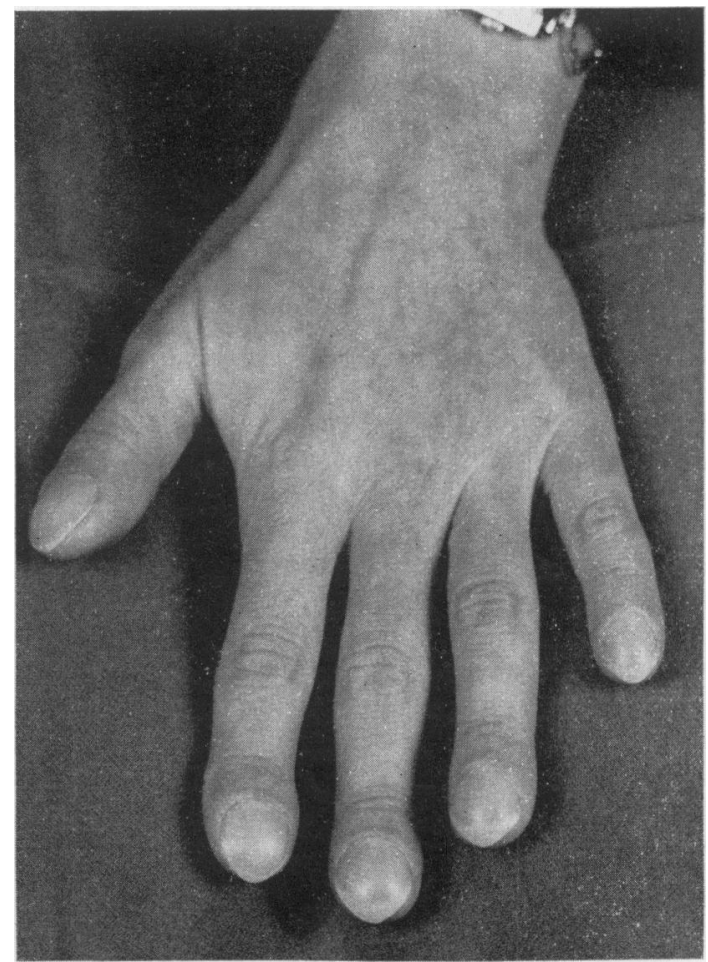

FIG. 2. The patient's hand, showing finger clubbing.

is $N$-aspartyl- $\beta$-glucosaminidase. This enzyme activity was measured in lymphocytes isolated from the patient's blood by the Ficoll-Metrizoate (Lymphoprep $\left.{ }^{\circledR}\right)$ method. Normal enzyme activity was found.

Because of the previous anorexia nervosa, laxative abuse was suspected. When specifically questioned on this, the patient reluctantly admitted the daily intake of 2 to 5 tablets of a senna preparation (Pursennid ${ }^{\circledR}$, containing $12 \mathrm{mg}$ senna glycoside per tablet) continuously for 10 years. She was strongly advised to discontinue this habit. The probable connection between the laxative and the disfigured fingers was pointed out, and other hazards of laxative abuse were mentioned. Later however, she reported that she was unable to discontinue the senna tablets because attempts to do so caused severe constipation. Bulk laxatives had no effect.

\section{Discussion}

It was apparent that the patient had an abnormality similar to aspartylglucosaminuria. However, mental retardation and facial abnormalities were conspicuously absent. The intermittency of aspartylglucosamine excretion as well as the normal 
enzyme activity excluded true genetic aspartylglucosaminuria and suggested an acquired disturbance.

The liver biopsy findings were similar to those reported in genuine aspartylglucosaminuria (Isenberg and Sharp, 1976), except that no PAS positive globules or vacuoles were detected in the hepatocytes.

It seems highly probable that the patient's finger clubbing was caused by her long-term laxative abuse. It is interesting to note that patients with senna-related finger clubbing reported by Silk et al., (1975), and by Prior and White (1978), had features of anorexia nervosa. Thus, both malnutrition and laxative abuse may be necessary to produce this physical abnormality. However, in the present patient, finger clubbing has been maintained after the cessation of anorexia. The cause of her intermittent fluid retention is less evident.

It seems that the patient's laxative addiction has produced a partial phenocopy of aspartylglucosaminuria. The intermittent excretion of this metabolite and the finger clubbing, curved radii, and abnormal liver histology are unlikely to be a chance combination. A disturbance in the turnover of glycoproteins may well be expected to cause connective tissue abnormalities. The nature of the $\bar{z}$ relation to senna alkaloid ingestion is unknown $\stackrel{\varnothing}{\varrho}$ and would deserve further study.

\section{Acknowledgment}

We wish to thank Dr S. Autio, Children's Hospital, University of Helsinki, for carrying out the assay on enzyme activity.

\section{References}

Autio, S. (1972) Aspartylglucosaminuria. Analysis of thirty-four patients. Journal of Mental Deficiency Research, $\stackrel{\odot}{\circ}$ Monograph Series. I.

BARKA, T. \& ANDERSSON, P.J. (1962) Histochemical methods $\vec{\omega}$ for acid phosphatase using hexazonium pararosanilin as coupler. Journal of Histochemistry and Cytochemistry, 10, 741.

ISENBERG, J.N. \& SHARP, H.L. (1976) Aspartylglucosaminuria: Unique biochemical and ultrastructural charac- or teristics. Human Pathology, 7, 469.

JenNer, F.A. \& Pollitt, R.J. (1967) Large quantities of $\mathrm{N}$ 2-acetamido-1-( $\beta^{1}$-L-aspartamido)-1,2-dideoxyglucose in $\infty$ the urine of mentally-retarded siblings. Biochemical $\mathrm{N}$ Journal, 103, 48P.

PrIOR, J. \& WHITE, I. (1978) Tetany and clubbing in a patient who ingested large quantities of senna. Lancet, ii, 947.

Silk, D.B.A., Gibson, J.A. \& Murray, C.R.H. (1975) Reversible finger clubbing in a case of purgative abuse. Gastroenterology, 68, 790. 